\title{
O espírito da Estética
}

\section{Farlley Derze}

Músico, doutor pela FAU/UnB, mestre em Educação Musical pela UnB, professor de História da lluminação e Metodologia do Trabalho Científico do Instituto de Ensino Superior Brasileiro.

\section{Resumo}

A Estética ganhou autonomia no iluminismo. A Estética se torna uma Disciplina que vem provocar a visão que os filósofos da época tinham não somente sobre a arte do passado, mas também sobre os artistas e suas obras. Cabe observar que uma "autonomia da Estética" não tem o mesmo significado de "autonomia da arte". A ideia de Estética, num senso moderno, diz respeito a uma arte que, para além de ser vista como uma atividade ligada a determinadas técnicas, passa a ser reconhecida também como atividade intelectual. Assim, a imitação da natureza ou imagens encomendadas não seriam mais consideradas a única finalidade do artista. Com a Estética, o artista, progressivamente, se liberta das tutelas teológicas, metafísicas, morais, sociais ou políticas, rumo a um caminho de liberdade criativa.

Palavras-chave: Estética. Baumgarten. Sensações. Arte. 
Cruzando por uma praça ontem no caminho de casa, notei uma idosa sentada ao ar livre. Era fim de tarde de sol morno. Minha atenção foi atraída pela algazarra de um grupo de jovens, desses que não estão nem aí e, aos cochichões e gargalhadas, se dirigiram à velha senhora para lhe dizer "procura outro lugar pra pensar"! Eu estava a uma certa distância e não deu tempo de reagir, pois a velha senhora já se levantava, equilibrava-se com uma bengala, e sem olhar para os rapazes se afastou dali. Caminhou a passos lentose difíceis enquanto às suas costas ecoavam as gargalhadas cínicas dos adolescentes. Vários bancos na praça estavam ocupados, exceto um para o qual ela se dirigiu lentamente. Resolvi ir em sua direção e perguntar-lhe se precisava de alguma ajuda. Era também uma forma de mostrar aos meninos abusados que ela não estava sozinha, e assim fazerIhes crer que seria boa ideia deixá-la quieta. Apertei meu passo de modo que minha chegada ao outro banco da praça coincidisse com a dela. Quando a alcancei, ajudei-a a se sentar e cumprimentei-a. - Boa tarde, senhora.

- Boa tarde, meu filho, respondeu com alguma dificuldade de respirar.

Quando nos acomodamos, esperei que ela recuperasse o fôlego. Então me apresentei. - Meu nome é Jefé Mavi. Posso lhe fazer companhia? - Ah, com muito prazer, meu filho. Chamo-me Estética.

Ela percebeu que levantei minhas sobrancelhas ao ouvir seu nome. Ela também levantou as dela com um sorriso de canto de boca, um sorriso gentil. - Que nome interessante- comentei.

Ela agradeceu. Não parecia estar a fim de conversar. Olhava as nuvens, olhava os pássaros que voavam entre as árvores e depois de algum silêncio disse que meu nome também era interessante.

- Se um francês ouvisse o seu nome, meu filho, poderia traduzi-lo como "eu faço minha vida" (Jefé Mavi - Je fais ma vie).

Eu dei um sorriso mais aberto e comentei que já haviam me dito aquilo. Ela deu de ombros como quem diz "é óbvio". Então, lhe perguntei o que ela considerava óbvio tendo em conta sua experiência de vida. Prontamente respondeu.

- Meu parteiro, Alexander Gottlieb Baumgarten, no dia em que nasci, não fazia parte dos filósofos célebres. Isso era óbvio.

Balancei a cabeça como quem concorda, mas lá dentro estava morrendo de curiosidade se ela estaria sendo irônica, ou não. Balancei minha cabeça feito um boneco de mola que foi acionado por um peteleco e, subitamente, ela me perguntou:

- Você já ouviu falar de Baumgarten, Alexander Gottlieb Baumgarten?

Então balancei minha cabeça positivamente com certa timidez. Ela notou. Fez outra pergunta como se estivéssemos no aquecimento de uma conversa: - Você viu aqueles rapazes me expulsarem daquele banco onde eu estava sentada?

Eu menti. Disse que não tinha visto. O que ela pensaria de mim se dissesse que tinha visto aquela cena e não fizera absolutamente nada, mesmo a uma relativa distância de onde me encontrava?

- Pois bem - ela disse. - Escute-me. Enquanto eu caminhava daquele banco até este aqui eu exercitava uma resposta para o que me disseram: "procura outro lugar pra pensar".

Daí lançou-me um olhar instantâneo ao mesmo tempo que finalizou a frase, um olhar de olhos esbugalhados, grandes, redondos, provocativos, e tinha os lábios apertados com os dentes como quem diz "isto não teria uma resposta óbvia, teria"?

Eu arregalei meus olhos por puro reflexo ou empatia. Depois os cerrei sutilmente sem disfarçar minha dúvida. Ela sabia que eu não tinha pescado o "x" da questão.

Ergueu sua bengala e deu dois toques em meu joelho, depois apontou a bengala para o outro lado da praça a me mostrar que aqueles adolescentes estavam indo embora. Ao descer sua bengala fez um círculo na areia, entre seus pés.

- Isso é óbvio pra você- perguntou sem me olhar.

- O que? - respondi. - O círculo?

Ela explodiu numa gargalhada que mexia todo seu corpo, os ombros, os joelhos, a cabeça. Obviamente 
não entendi. Ela se recompôs e explanou-me: - Primeiro, perdoe-me meu filho. Não ri de você. Lembrei-me do meu parteiro, Baumgarten. Foi prazeroso vir ao mundo com uma espécie de missão, a de propor uma relação entre três domínios até então vistos como autônomos: a arte, o belo e os sentidos. E assim, oferecer uma identidade filosófica a esses três objetos.

Eu tentava acompanhar seu raciocínio, então lhe perguntei:

- Qual era a sua preocupação com a frase "procura outro lugar pra pensar"?

- Ah, sim - respondeu enquanto fazia um esforço com a bengala que estava emperrada na tentativa de escavar mais fundo o círculo desenhado na areia. $\mathrm{E}$ continuou. - Eu já ia me esquecendo desse assunto. Pense comigo: esse lugar pra pensar seria na mente ou um lugar físico? Um lugar concreto, material, um sofá, ou seria um lugar metafísico, abstrato, imaterial, um espaço no intelecto? "Procura outro lugar pra pensar" poderia ser "procura outra ideia, outra lógica, outro argumento, outro método de pensar". - Concluiu sua resposta sem interromper o movimento de círculo que fazia na areia da praça com sua bengala.

Eu acho que estava entendendo o que ela queria dizer. Se eu quiser pensar no círculo que ela riscou no chão, ele tem um tipo de valor, ou importância, se o pensamento é ocupado por ideias matemáticas. Ao se buscar outro lugar no pensamento, como o desenho ou a arte, o círculo assume outro valor. Não sei se a palavra é valor, ou função, ou importância. Mas um círculo pode ser pensado de um jeito por um matemático, e de outro por um artista. Em termos concretos, sensíveis, não deixa de ser um círculo. "Outro lugar pra pensar" seria uma provocação para se explorar os corredores da mente. Com essa abordagem, gosto de pensar na mente, em sua dimensão abstrata, como um espaço arquitetônico. Há pessoas cuja mente poderia ser um cemitério. Outras, uma mente mais parecida com uma catedral, de pé-direito alto, ecos e vitrais. Pode haver mentes com janelas abertas, ou janelas com grades, ou sem janelas, sem luz... um lugar acostumado ao mofo. Absorto, expus esses pensamentos à Madame Estética. Ela parou de riscar o chão com sua bengala. Virou sua cabeça em minha direção e deu uma piscadela para mim. E disse:

- Agora substitua a ideia de círculo pela ideia de moderno, isto é, se um círculo pode ter uma representatividade diferente no pensamento de um matemático ou de um artista, o que seria representativo do conceito de moderno? - A senhora quer uma resposta agora? - indaguei. - Eu adoraria lhe ouvir, meu filho. - Disse-me com um olhar terno.

Houve uma pequena pausa, um silêncio no ar. Eu buscava organizar minhas ideias. Ela percebeu uma certa ansiedade em mim, e perguntou-me: - Você é matemático ou artista? - E continuou. - Existe matemática moderna? Existe arte moderna? - E concluiu com outra pergunta. - Qual é sua profissão? Deixe-me saber como é a arquitetura de sua mente? - Sou professor universitário e pertenço a um grupo de estudos sobre estética, semiótica e hermenêutica.

Ela correu seus olhos em mim, apertou os lábios com os dentes, reposicionou sua cabeça como quem busca um melhor ângulo para me olhar e perguntou-me: - Eu lhe conheço?

Ela não parecia tão interessada numa resposta. Ajeitou-se no banco e após demonstrar que estava mais acomodada cobrou-me a resposta do assunto anterior.

- Então diga-me, meu filho. - Falava num tom de voz suave. - O que significa o termo moderno?

Eu não tinha essa resposta na ponta da língua. Estava começando a escurecer e, além disso, o tempo virou, um vento soprava mais forte e noutra temperatura. Então lhe perguntei se aceitaria ir a outro lugar. Ela sugeriu um café.

Havia um café próximo dali, a duas quadras da praça. Ela não quis tomar um táxi. Disse que precisava fortalecer os músculos das pernas. Durante nossa caminhada até o local, notei que ela cantarolava o terceiro movimento da terceira sinfonia de Brahms. Fazia pequenas pausas para descansar, mas não interrompia a melodia. Em certas horas erguia a bengala como se estivesse regendo uma orquestra. Eu sorria e sentia uma espécie de paz ao lado daquela senhora. Ah se estivesse com uma câmera fotográfica. As luzes dos postes já estavam acesas. Madame Estética parecia flutuar enquanto cantarolava. A cor azulada da noite começava a esconder as nuvens do céu. Enquanto ouvia aquela melodia de Brahms, me perguntei se tal melodia seria moderna comparada ao 
canto medieval. Já li a biografia de Brahms e minha indagação não fazia sentido, porque é sabido que ele era considerado um compositor "tradicional", portanto longe de ser "moderno" ou estar afinado com as tendências de seu tempo. Mas a indagação fazia sentido se as lentes não fossem apontadas para Brahms, mas para a melodia em questão que, seguramente, é moderna comparada ao canto gregoriano. Eu queria achar um meio de fazer uma autópsia, uma dissecação no conceito de "moderno". Ou melhor, um exame anatômico já que autópsia se aplica a seres mortos e o termo "moderno" parece viajar eternamente num tapete voador nos sopros do futuro.

Chegamos ao café. Pedimos dois capuccinos. Ela lembrou-se de um sonho esquisito. Sonhou que estava no mundo paleolítico e nenhum Homo Erectus notou sua presença enquanto pintavam as paredes da caverna. Eu perguntei o que mais tinha no sonho. Ela disse que imaginava o que diria Monet caso estivesse ali no meio daqueles homens dentro da caverna. Perguntei por que Monet. Ela disse que foi o nome que Ihe veio à cabeça no sonho, mas poderia ser um Renoir, um Da Vinci ou um Malevich. Deu um suspiro e disse que nenhum deles apareceu no sonho. Perguntei-lhe por que achava o sonho esquisito. Ela disse que viu traços de arte contemporânea ali nas paredes, algo como um "happening", uma espécie de "expressionismo concreto", um estilo pré-Pollock.

Dei um gole no meu café e disse-lhe a verdade. Eu não tinha na cabeça um conceito fixo para o termo "moderno". Todavia, o conceito de moderno, bemdizer, é escrutinado pela literatura como se quisessem Ihe dotar de materialidade. Um historiador do conceito de "moderno" poderia concluir que o significado deste termo não poderia morar esmagado numa página do dicionário. É um conceito poroso, gasoso na atmosfera de cada época, tal qual tem sido a dificuldade em se conceituar "arte" e "beleza". É comum se ver na diversidade social o uso do termo moderno associado a outros como tecnologia, mecanização, industrialização. Quando se menciona o termo "moderno", parece que se leva em conta o momento em que os ponteiros de um relógio pulam para determinada situação que não existia. A máquina de datilografar já foi moderna e um dia o notebook será peça de museu; a lâmpada incandescente já foi moderna e um dia os LEDs serão peças de museu; a pintura renascentista foi moderna se comparada aos traços medievais, Mas um Da Vinci não seria moderno na visão dos impressionistas.
No fundo, os termos “moderno", "arte”, "beleza" são conceitos abstratos se comparados a termos como "chuva", "nuvem”, "martelo".

No ano de 2014, propus a quarenta e cinco arquitetos do Rio de Janeiro e quarenta e cinco da cidade de Natal, RN, todos alunos em um curso de pósgraduação do qual era docente, que propusessem sinônimos para o termo moderno. Eis alguns: mobilidade, mudança, movimento, momento, mutação, máquinas, metrópole, originalidade, otimização, ostentação, diversidade, desenvolvimento, design, descarte, descoberta, digital, evolução, expansão, eletricidade, revolução, razão, rapidez, reciclagem, revelação, realidade, ruptura, novidade, novo, inovação, industrialização, iluminação, intervenção, invenção, desafio, duvidoso, desconstrução, adaptação, avanço, atual, dinamismo, diferença, desenvolvimento, exploração, expectativa, encantamento. Abri meu celular e mostrei essa lista à Madame Estética. Ela comentou:

- Parece o vocabulário de uma época. - Disse com sua xícara suspensa no ar. Olhou-me com um sorriso escondido, como quem brinca com os pensamentos e disse:

- Que palavras sobre o termo "moderno" sairiam num bate-papo entre Le Corbusier, Niemeyer, Bruno Zevi, Zaha Mohammad Hadid, Calatrava, Amanda Levete, Elissa Aalto, durante um café? Que palavras representariam um objeto em sua materialidade, quais representariam uma abstração, uma ideia em sua vontade de potência? Quem diria o quê?

Aproveitei o gancho e balancei no ar uma pergunta à queima-roupa?

- Por falar em quem diria o quê - falei com firmeza enquanto tocava delicadamente nas mãos daquela senhora - quem fala o quê sobre a senhora? - E mantive por alguns segundos minha mão sobre a mão dela. Depois retirei-a como quem se prepara para ouvir a resposta.

- Eu adoraria saber o que vocês, do grupo a que você pertence, Estética, Semiótica e Hermenêutica, falam a meu respeito.

Disse com uma feição serena. E colocou a batata quente na minha mão:

- Diga-me você. O que você acha que eu sou? 
Eu balançava minha cabeça para frente e para trás como um joão-teimoso, quase um tique nervoso tamanho o meu entusiasmo como aquele encontro, e ser desafiado a dizer o que penso a respeito dela. Ela pediu licença para ir à toalete. Fiquei ali ruminando uma resposta, organizando as ideias, e me senti como se estivesse agarrado a uma boia no meio do oceano e tentando decidir para onde nadar. Tinha a sensação de que apesar dos livros já lidos sobre o assunto, apesar das aulas universitárias com professores interessantes, apesar da troca de ideias com artistas, leitura de artigos acadêmicos, bate-papo com colegas, era como se a boia fosse inútil naquele mar de informações espumosas. Dei um gole definitivo no meu capuccino e pedi ao garçom um espresso duplo sem açúcar para acalmar minha ansiedade. Chovia lá fora na noite urbana. Pela vidraça embaçada do restaurante, os faróis dos automóveis se cruzavam como pincéis de uma tela impressionista. Aquilo me acalmou. Madame Estética voltou. Puxei sua cadeira e ajudei-a a ocupar seu lugar. Ainda de pé, puxei meu lenço e passei atrás de meu pescoço. Guardei-o no bolso, sentei-me, tomei um gole do meu café e iniciei minha exposição.

- Olhe através daquela janela - pedi à estimada senhora. E perguntei-lhe - o que vê?

- Vejo uma tela futurista - respondeu-me como quem gosta de um jogo.

-É moderna?

- Por que não, meu filho?

- Se temos uma janela ou uma tela futurista, depende de como se vê.

- Perfeito, meu filho.

- Tem gente que lhe vê como sinônimo de beleza. Disse-lhe com vontade de ver sua reação.

Ela retorceu o nariz e apertou os olhos como quem escapa de um spray.

- Tem até clínica de estética - provoquei.

Ela deu um suspiro irônico.

- Eu não lhe interpreto como sinônimo de beleza, tampouco como uma entidade material como um martelo. Ninguém pode ir ali para comprar meio quilo de estética, ou uma estética azul ou perfumada, ou salgada, ou áspera ou assobiada.

Tomei outro gole do café. Notei um sorriso dela... silencioso, de canto de boca. E continuei:

- A senhora percebeu que eu citei os cinco sentidos (visão, olfato, paladar, tato e audição). E veja bem, não sou eu quem diz, mas li que já nos tempos dos gregos o seu nome fazia alusão aos sentidos (aisthesis), uma espécie de porta de entrada para a experiência de um conhecimento sobre o mundo ao redor. Embora o termo "aisthesis" existisse, permaneceu como entidade conceitual separada de outros conceitos abstratos como "arte" e "beleza". É como se a "aisthesis" fosse para as coisas do dia a dia. O termo "aisthesis" foi adotado por um alemão do século XVIII, cujo nome a senhora já mencionou. Ele tinha um interesse científico sobre as sensações, algo como "ciência das sensações" como uma tentativa de se obter o controle exato do conhecimento sensível. E aí, ele riscou o seu fósforo. Ele redefine o conceito de belo. Moderniza-o. Permita-me citar um colega acadêmico.

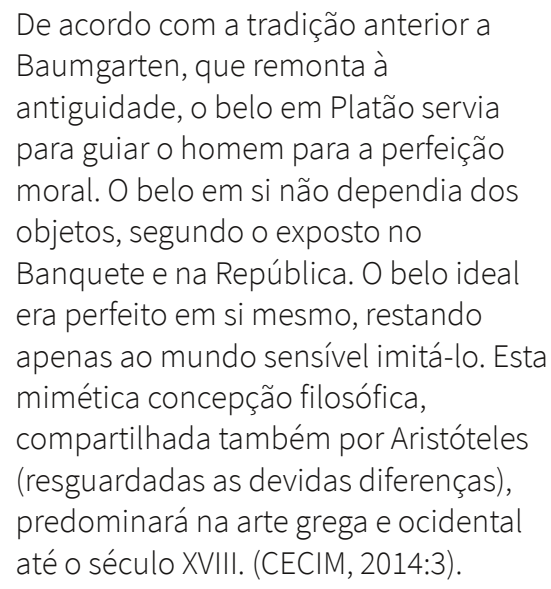

- O que você quis dizer quando fala que Baumgarten riscou o seu fósforo? - Perguntou-me animada, aquela incrível senhora.

- Quis dizer que Baumgarten retira o "belo" de sua condição utilitarista ou moral à la grega, e converte o belo numa espécie de metodologia da cognição do funcionamento de nossas sensações perante uma obra de arte. É como se tivesse entrado num laboratório e colocado dentro de um tubo de ensaio, a "arte", o "belo" e as nossas "sensações", com o interesse em sacudir o tubo de ensaio e acionar o relógio para medir quanto tempo a mistura fica homogênea. Dentro desse raciocínio, é como se Baumgarten quisesse dar uma cientificidade para identificar, ou melhor, descobrir como se pode identificar "o belo na arte" por meio de nossas sensações. Isso não caiu de paraquedas na mente dele. Ele estava numa época pós-cartesiana, portanto, herdeiro de um espírito científico de um período que sofrera transformações com novas propostas de se fazer ciência, com experimentos à base de coleta de dados como fizeram Newton, Descartes, Galileu, etc. em que tomavam nota, comparavam as coincidências, observavam a taxa de frequência de determinado 
fenômeno natural. Seguindo tal influência, Baumgarten acreditava que em vez de lidar com fenômenos naturais, poderia lidar com fenômenos metafísicos, com dados abstratos, subjetivos como o prazer, o gosto, todavia, com interesse em objetivá-los "cientificamente". Findou por inaugurar uma espécie de "filosofia da arte", porque se fosse adotar uma expressão do tipo "ciência do belo" era bem-dizer um oxímoro, um tipo de paradoxo que daria mais trabalho para demonstrar e explicar. Ocorre que a filosofia naqueles dias, ou até aqueles dias, não se preocupara se havia alguma lógica amalgamada entre "a arte", "o belo" e "as nossas sensações". De posse do termo "aisthesis" que dormia nos porões da Grécia antiga, Baumgarten imaginou que as sensações pudessem oferecer um caminho mensurável, controlável, para se conhecer aquilo que seja "o belo" na "arte" a partir do mundo sensível. Isso acendeu uma fogueira dentro da filosofia. Junto com o fogo vem a fumaça e Baumgarten entra para a história com seu fósforo guardado dentro da mão. A discussão tornou-se longa. A combustão de ideias se debruçou em questões de gosto, do juízo e da crítica. Permita-me finalizar esse esboço com um exemplo prático. Quando numa casa há vazamentos que indicam problemas na tubulação, chama-se um bombeiro hidráulico. Este não inventou o cano nem criou a água, mas conhece o funcionamento de tubulações numa casa. Quando numa casa o telhado está com problemas, chama-se alguém que conheça de telhados mesmo que não seja o inventor da argila nem o inventor de telhas. Quando um piano está desafinado, chama-se um afinador, pois embora este não tenha inventado o piano nem o sistema de afinação, conhece o funcionamento das cordas em um piano. Quando no mundo da arte há problemas relacionados às preferências pessoais sobre o que se considera belo, chama-se a Estética que foi criada com o intuito de explicar o funcionamento de como uma pessoa considera algo belo na arte, por meio de um exercício que une a esfera sensível à racional. Passo a palavra a um colega acadêmico:

Não se pode subestimar a importância da instituição Estética como disciplina filosófica, por parte de Baumgarten. 0 resultado desse acontecimento pode ver-se tanto no reconhecimento do significado desse campo de problemas e de vivências, agora apreciados em toda a sua dignidade e importância filosófica, quanto no efeito que isso viria a ter na transformação da própria ideia de filosofia. Esta deixará de medir-se preferentemente como a Matese e a

Geometria, como sendo os seus

paradigmas de cientificidade (assim o

fora desde o século anterior, com

Descartes, Hobbes, Espinosa, Leibniz...), e passará a medir-se antes pela Poesia e pela Arte, como se fossem o seu

organon e a conceber-se ela mesma como sendo obra não do trabalho mecânico do entendimento segundo regras determinadas, mas como criação e desenvolvimento espontâneos do "gênio da razão" (SANTOS, 2010:39).

- Em suma, em vez de se perpetuar uma lógica consagrada historicamente, com a qual se estava habituado, a Estética se oferece numa lógica fenomenológica. Quer dizer, a Estética é menos algo existente no objeto e mais algo existente no sujeito. $A$ Estética, como parte da filosofia, seria um novo método de se pensar, de se produzir reflexões sobre a arte desde o pavio aceso em nossa realidade sensível até seu estrondo na nossa dimensão racional. O belo, enquanto método de raciocínio, ou reflexão, ou exercício de uma consciência cria um vínculo entre o objeto (coisa sensível) e o sujeito (racional). Belo como consciência do funcionamento da percepção, de seu estágio mais básico - o mundo sensível - ao mais refinado, a razão e suas representações. Portanto, é menos a beleza das coisas e mais a beleza de um conhecimento (de uma ideia?).

A velha senhora me ouvia atentamente. Fiz um olhar como quem tentou mostrar em que ponto se encontra minha interpretação sobre ela - a Estética, consciente de que falava coisas nadando em muitas espumase sem saber se alcançaria a enseada. Ela esticou suas mãos e pousou-as sobre as minhas. Disse-me:

- Vocêse lembra daqueles rapazes lá da praça que me disseram "procura outro lugar pra pensar"?

- Sim, lembro-me deles.

- Pois bem. Eles eram os sentidos. Faz parte da minha condição receber uma exigência deles para, a partir deles, avançar, cruzar o mundo natural em busca de um conhecimento sobre alguma coisa, no meu caso, a arte. Pois esta funciona como isca para se percorrer um trajeto entre um mundo tangível e um mundo inteligível, ou do mundo sensível ao racional. Bemdizer, minha existência é um tipo de exercício como se fosse possível "sentir" a razão. 
Ao dizer isso, a velha senhora se levantou, olhou para a porta, me pediu um abraço e me disse adeus. Eu lhe ofereci uma carona. Ela sorriu e disse que nasceu para caminhar. Ainda chovia naquela noite e vi sua silhueta desaparecer pouco a pouco, cruzando as poças de luzes afogadas no asfalto. É como se ela quisesse, também, explorar aquela sensação - a arte de viver.

\section{Referências}

CECIM, Arthur Martins. Baumgarten, Kant e a teoria do belo: conhecimento das belas coisas ou belo pensamento? In: PARALAXE. v. 2, n. 1, 2014. Programa de Pós-Graduação em Filosofia da Universidade Federal do Pará - UFPA, Belém, Pará, Brasil.

SANTOS, Leonel Ribeiro dos. A concepção kantiana da experiência estética: novidades, tensões e equilíbrios. In: Trans/Form/Ação, Marília, v.33, n.2, p. 35-76. CFUL - Faculdade de Letras da Universidade de Lisboa, 2010. 
74 Revista Estética e Semiótica | Volume 8 | Número 1 